\title{
SENTENCIA SOBRE RESCISIÓN DE PARTICIÓN HEREDITARIA (CORTE DE APELACIONES DE TEMUCO)
}

\author{
Comentario de Juan Andrés Varas Braun
}

"Temuco, cinco de septiembre de dos mil cinco.

VISTOS:

Se reproduce la sentencia en alzada, con las excepciones que se indican a continuación:

a) Se eliminan los siguientes considerandos: desde el fundamento segundo hasta el quinto; y desde el séptimo hasta el décimo séptimo;

b) En la motivación primera, en el párrafo signado con el número "Tres”, se eliminan las frases que comienzan con la palabra "sentencia”, después de la cifra "2002", y que concluye con un punto seguido, después del apellido "Zamora”. Asimismo, en el acápite signado con el número "Cuatro", se suprime la frase que comienza con la expresión "ninguno" y concluye con el vocablo "legal", seguido de un punto. Por último, en el capítulo numerado como "Cinco", se elimina toda su parte final, que se inicia con las palabras "Los bienes" y concluye con el pronombre "él”, seguido de un punto aparte;

c) En el fundamento sexto, se elimina todo el párrafo signado con el número "Uno"; y en el apartado "Dos" se sustrae la frase que se inicia con las locuciones "En efecto" y finaliza con el vocablo "pagadora", seguido de un punto;

d) Se suprimen las citas de los Arts. 19 N 24 de la Constitución Política de la República, 2314, 2317, 2320, 2322, 2329 y 2332 del Código Civil, y 8 y 698 del Código de Procedimiento Civil;

\section{Y SE TIENE, EN SU LUGAR, PRESENTE:}

$1^{\circ}$ Que en el presente juicio se acciona por el demandante a fin de que se declare la nulidad absoluta de la partición conocida y fallada por el juez árbitro don Hernán Patricio Pinilla Zapata, y en subsidio, que se rescinda por lesión enorme, acción que prevé el artículo 1348 del Código Civil, en cuanto expresa que: "Las particiones se anulan o rescinden de la misma manera y según las mismas reglas que los contratos. La rescisión por causa de lesión se concede al que ha sido perjudicado en más de la mitad de su cuota"; y cuyos fundamentos se expresan en lo expositivo de la sentencia recurrida; 
$2^{\circ}$ Que como ha quedado asentado en el considerando primero del fallo de primer grado, son hechos de la causa que la comunidad hereditaria, formada por los bienes que allí se indican, tiene un haber líquido de \$227.120.923; “que conforme al informe pericial de tasación, presentación de fs. 207 del expediente particional y la escritura pública de protocolo de partición parcial acompañado de fs. 263 a 268 y de 271 a 277 de autos, el juez partidor resolvió formar las hijuelas de cada interesado de manera tal que con su valor de tasación y la adjudicación de ellas en dominio se enteran los derechos de cada uno". A su vez, en el numeral seis del aludido considerando, se expresa también que es un hecho del proceso "que como resultado de la subdivisión de la hijuela $\mathrm{N}^{\circ} 5$ se crearon los lotes $\mathrm{N}^{\circ} 1$ al 5, adjudicándose el lote $\mathrm{N}^{\mathrm{o}}$ 3, en comunidad a don Víctor Hugo Bernales Villalobos y a doña Hevelin Gloria Betancourt Mainhard; el Lote $\mathrm{N}^{\circ} 1$ y las acciones y derechos sobre el inmueble ubicado en la comuna de Villarrica a doña Orfelina del Carmen del Carmen Villalobos Carrasco; el Lote $\mathrm{N}^{\circ} 4$ y la hijuela $\mathrm{N}^{\circ} 6$ a don Luis Osvaldo Bernales Villalobos; y el Lote $\mathrm{N}^{\circ} 2$ a don Osvaldo Armando Bernales Zamora".

Finalmente, es un hecho no controvertido que el demandante es titular de una cuota ascendente al $10 \%$ de la masa, en su calidad de hijo de filiación no matrimonial del causante Juan Bernales Rosas;

$4^{\circ}$ Que respecto del primer motivo de nulidad absoluta de la partición esgrimido por el actor, esto es, que la adjudicación del lote $\mathrm{N}^{\circ} 5$ al demandado y árbitro partidor don Hernán Patricio Pinilla Ascencio adolece de objeto ilícito al establecerse los honorarios del árbitro no por acuerdo unánime ni propuestos en el laudo y ordenata, será desestimada teniendo únicamente presente que, como consta del proceso, las partes acordaron dichos honorarios en una de las audiencias del juicio particional; y que, con todo, tanto dicho acuerdo constituye una actuación procesal que debe objetarse a través de los incidentes o medios de impugnación respectivos in limine litis. Por tanto, si hubo alguna actuación viciada en el juicio -como la no asistencia de todos los interesados al comparendo en que se celebró el acuerdo- o no era procedente que el árbitro fijara sus honorarios en la sentencia definitiva, son cuestiones meramente procesales que debieron alegarse en su oportunidad, y que quedaron definitivamente saneadas con la sentencia firme; y por la misma razón, no logran constituir vicios de nulidad substantivos.

En cuanto a los demás motivos de nulidad absoluta invocados, se estará a lo resuelto en el fallo de primer grado;

$5^{\circ}$ Que subsidiariamente, el demandante accionó de rescisión por lesión enorme, que le concede el inciso segundo del Artículo 1348 del Código Civil, en cuanto preceptúa que la rescisión de la partición procede respecto del que ha sido perjudicado en más de la mitad de su cuota.

Dicha acción, como apunta el profesor Somarriva, se aplica a toda clase partición, tanto a la hecha por el causante, por los comuneros de común acuerdo o por el partidor, y en este caso, "no es óbice para demandar la nulidad de la partición fundada en el artículo 1348 el hecho que el laudo se encuentre ejecutoriado y aun aprobado judicialmente", agregando que "la solución contraria equivaldría a transformar la nulidad civil en procesal, 
ya que se sanearía con la ejecutoria del laudo" (Manuel Somarriva Undurraga, Indivisión y Partición, tomo II, pags.393 y 394. Edit. Jurídica de Chile, año 1956);

En consecuencia, habrá de determinarse si se encuentra probado en autos que el bien hereditario adjudicado en la partición al demandante (Lote $\mathrm{N}^{\circ} 2$ de 10.882 metros cuadrados de superficie) es inferior a la mitad de su cuota de un $10 \%$ de los bienes partibles, esto es, inferior a la mitad de $\$ 22.712 .092$, de acuerdo al monto del haber líquido de la comunidad;

$6^{\circ}$ Que sobre el particular, el tribunal tiene presente que la determinación del valor de los lotes adjudicados a los comuneros tuvo como base el proyecto de subdivisión de las Hijuelas $\mathrm{N}^{\circ} 5$ y $\mathrm{N}^{\circ} 6$, así como la tasación de los bienes hereditarios, efectuada por el perito Marcelo González Palma a fs. 179 y 186, y rectificado a fs. 244 , del expediente sobre juicio de partición tenido a la vista. Dicho informe y su rectificación fueron aprobados por todos los comuneros -con excepción del demandante Osvaldo Bernales Zamora- en una escritura pública denominada "Protocolo de partición parcial en sucesión de don Juan Osvaldo Bernales Zamora” (Fs. 263 a fs. 268 del mismo expediente), y que el juez árbitro consideró como base de la división y adjudicación de los lotes, como expresamente señala en los fundamentos sexto, undécimo, y duodécimo al décimo sexto del laudo y ordenata;

$7^{\circ}$ Que como puede apreciarse de dicha pericia - no aceptada por el actor- y del laudo y ordenata, al demandante se le adjudicó el Lote $\mathrm{N}^{\circ} 2$ del de la división de las Hijuelas $\mathrm{N}^{\circ} 5$ y $\mathrm{N}^{\circ} 6$, ubicadas a orillas del lago Calafquén, cuya superficie total asciende a 46 hectáreas; lote que asciende a una superficie de $10.882 \mathrm{~m}^{2}$, valorados en $\$ 22.712 .200$.

En cuanto a los demás comuneros, la cuota hereditaria correspondiente a don Víctor Bernales Villalobos y Hevelin Betancourt Mainhard, que asciende al 20\% del total, se le entera con el Lote $\mathrm{N}^{\circ} 4$, de 258.000 metros cuadrados de superficie, tasada en $\$ 45.524 .185$ menos un alcance por $\$ 21.609 .700$ que les enteran el comunero Luis Bernales Villalobos, pagándolo en dinero efectivo; la cuota hereditaria de doña Orfelina Villalobos Carrasco, correspondiente al $50 \%$ del total, esto es, $\$ 113.560 .400$, se le entera adjudicándole el Lote $\mathrm{N}^{\mathrm{o}} 1$, de $44.580 \mathrm{~m}^{2}$, tasado en $\$ 54.045 .400$, y el saldo con unas acciones y derechos del causante en unos sitios de la ciudad de Villarrica; al comunero Luis Bernales Villalobos, por su cuota hereditaria ascendente al 20\%, que corresponde a $\$ 45.424 .185$, se le entera adjudicándole el Lote $\mathrm{N}^{\circ} 3$, de $86.009 \mathrm{~m}^{2}$, tasado en $\$ 12.864 .501$, y la Hijuela $N^{\circ} 6$, de 10,10 hectáreas, tasada en $\$ 10.950 .000$, más el alcance antes expresado por $\$ 21.609 .700$; y finalmente, la hijuela pagadora del tribunal arbitral, ascendente a $\$ 21.915 .177$ (que se considera baja general de la herencia), que se entera con la hijuela $\mathrm{N}^{\circ} 5$, de $57.984 \mathrm{~m}^{2}$, tasada en $\$ 21.915 .200$, menos un alcance en su contra por $\$ 1.992 .289$ y que se pagará en dinero efectivo;

$8^{\circ}$ Que siendo los principales bienes hereditarios las hijuelas $\mathrm{N}^{\circ} 5$ y $\mathrm{N}^{\circ} 6$, y enterándose las cuotas de los comuneros - salvo sólo parcialmente la de doña Orfelina 
Villalobos Carrasco-, así como los honorarios del tribunal arbitral, con la subdivisión de la primera de ellas en cinco lotes, más la segunda, resulta atendible el fundamento de la acción rescisoria por lesión enorme deducida por el demandante, y que se funda en que su cuota hereditaria de un $10 \%$, correspondiente a \$22.712.092 del haber líquido, se enteró con bienes por un valor inferior a la mitad de la misma; esto es, que el Lote $\mathrm{N}^{\circ} 2$, de $10.882 \mathrm{~m}^{2}$ que se le adjudica, es inferior en valor a la mitad de dicha cuota, esto es, inferior a $\$ 11.356 .046$; conclusión a la que se arriba en virtud de las reflexiones siguientes;

$9^{\circ}$ Que, en efecto, de la sola lectura de la sentencia recurrida, así como de la tasación pericial y subdivisión que le sirve de fundamento, surge una evidente desproporción de los lotes asignados, considerando la superficie de cada uno y en relación a los derechos de cada comunero. Así, aparece que al demandante se le adjudica el lote $\mathrm{N}^{\mathrm{o}} 2$, de $10.882 \mathrm{~m}^{2}$, esto es, 1,08 hectáreas. Siendo la superficie total de las Hijuelas $\mathrm{N}^{\circ} 5$ y $\mathrm{N}^{\circ} 6$ un total de 46 hectáreas, y considerando únicamente la superficie, debió corresponderle al demandante 4,6 hectáreas; en cambio, a los otros comuneros se les asignan, por el 20\%, el lote $\mathrm{N}^{\circ} 4$, de 25,8 hectáreas (Víctor Bernales y Hevelin Betancourt), y el lote $\mathrm{N}^{\circ} 3$ y la hijuela $\mathrm{N}^{\circ} 6$ (Luis Bernales), con una superficie total de 18,7 hectáreas; en circunstancias que a éstos comuneros, por sus cuotas de un $20 \%$, debió corresponderles 9,2 hectáreas en cada caso. Esta desproporción aparece también manifiesta si se compara el lote adjudicado al demandante con el del juez árbitro, cuya cuota sólo correspondía al 8\% (esto es, 3,68 hectáreas), y se le adjudica el lote $\mathrm{N}^{\circ}$ 5, de 5, 79 hectáreas;

$10^{\circ}$ Que la tasación y subdivisión en que se basó el fallo determinó distintos valores a los lotes haciendo una diferenciación de los suelos en clases A, B, C, y D considerando las aptitudes agrícolas, ganaderas, forestales y turísticas, además de otros factores, y asignando valores al metro cuadrado que en los casos de los suelos A, B, y C corresponden $\$ 6.000, \$ 2.500$ y $\$ 1.000$, respectivamente; y el clase $\mathrm{D}, \mathrm{a} \$ 100$. Sin embargo, la pericia en cuestión no resiste un análisis lógico ni racional al determinar diferencias tan enormes para suelos que pertenecen a un mismo predio, cuyos lotes en definitiva quedaron todos limitando por el norte con el Lago Calafquén. No puede sino contradecir al sentido común más elemental concluir que en esas condiciones existan suelos con valor \$ 6.000 el metro cuadrado, y otros cuyo valor es de $\$ 100$ el metro cuadrado. Considerando este aspecto, llama la atención que el lote de 1,08 hectáreas adjudicado al actor se compondría, aproximadamente en un $85 \%$, de suelos clase B (valorados en $\$ 2.500$ el metro cuadrado), en tanto que los suelos de los lotes adjudicados a los otros comuneros y al árbitro se componen en porcentajes que oscilan entre un 60 y un $80 \%$, aproximadamente, en suelos clase D, cuyo valor es de $\$ 100$ el metro cuadrado;

$11^{\circ}$ Que refuerza lo anteriormente razonado la circunstancia que el informe de tasación de fs. 98 a fs. 108, elaborado por la Ingeniero Agrónomo María Núñez Arroyo, y acompañado por una de las partes demandadas de autos, estima que aun cuando el 
destino del predio según el Servicio de Impuestos Internos es agrícola, la ubicación de la propiedad es óptima desde el punto de vista turístico por contar con vista a diversos volcanes y acceso a una playa (haciendo presente que según CIREN-CORFO son tierras que pueden cultivarse únicamente para establecer pastos o forestación, requiriendo de un manejo muy cuidadoso, debido a que tienen como factores limitantes la pendiente del terreno y susceptibilidad de erosión); factores que en definitiva considera para su valoración comercial.

Luego, fluye de lo anterior que la superficie de los predios en cuestión carece de aptitud agrícola y muy escasa desde el punto de vista ganadero y forestal, siendo esencialmente de aptitud turística; por lo que sus suelos deben tener valores aproximadamente iguales, sin las grandes diferencias que se les atribuyeron en la sentencia arbitral;

$12^{\circ}$ Que otro antecedente que abona la conclusión de que los suelos subdivididos y adjudicados en la partición tienen un mismo valor, y esencialmente aptitud turística, es la copia de inscripción de una escritura pública de compraventa de 9 de junio de 2000, que rola a fs. 310 del expediente particional tenido a la vista, y que recae en un predio de media hectárea que también deslinda con el lago Calafquén, y cuyo precio es de $\$ 40.000 .000$, esto es, el metro cuadrado asciende a $\$ 8.000$, valor que se consideró, evidentemente, en razón de la referida aptitud turística del inmueble y no agrícola, ganadera o forestal;

$13^{\circ}$ Que los antecedentes probatorios precedentemente analizados, consistentes en tasaciones periciales y copias de instrumentos públicos, constituyen presunciones judiciales que, por su gravedad, precisión y concordancia, permiten dar por probado que el lote $\mathrm{N}^{\circ} 2$ resultante de la subdivisión de la hijuela $\mathrm{N}^{\circ}$ 5, de una superficie de 10.882 metros cuadrados, adjudicado al demandante Osvaldo Bernales Zamora, tiene un valor inferior a $\$ 11.356 .046$, esto es, inferior a la mitad de su cuota de un $10 \%$ en la herencia; por lo que resulta acreditado que ha sido perjudicado en más de la mitad de su cuota;

$14^{\circ}$ Que así las cosas, han quedado justificados en el proceso los supuestos de la acción de rescisión por lesión enorme de la adjudicación y que prevé el Art. 1348 del Código Civil, por lo que será revocada la sentencia dictada por el juez a quo, y será estimada la demanda de autos en lo que a dicha acción se refiere;

$15^{\circ}$ Que sigue como necesaria consecuencia de lo anterior que, siendo la partición materia de la acción de nulidad ejercida en autos nula de nulidad relativa, no es posible estimar las demandas reconvencionales de indemnización de perjuicios por daño moral deducidas por los demandados de autos, tanto porque tal daño no puede derivarse del ejercicio de una acción consagrada en el ordenamiento jurídico -ya que como ha señalado Couture, el ejercicio de la acción no es más que una manifestación del derecho constitucional de petición-, no existiendo por tanto fuente alguna de la obligación de indemnizar; cuanto porque el acto atacado por la demanda efectivamente adolece de nulidad relativa, como se ha expuesto; 
$15^{\circ}$ Que todo lo anteriormente reflexionado lleva a este tribunal de alzada a la convicción de revocar la sentencia recurrida, como se dirá en lo resolutivo.

Y visto, además, lo dispuesto en los Arts. 1687, 1712 del Código Civil y 186 y siguientes del Código de Procedimiento Civil, SE REVOCA la sentencia apelada de once de junio de dos mil cuatro, escrita de fs. 202 a fs. 225 , y se declara en su reemplazo que se hace lugar a la demanda de fs. 3 a fs. 10, en cuanto por ella se ejerce la acción subsidiaria de rescisión por lesión enorme, debiendo las partes ser restituidas al mismo estado en que se hallarían de no haber existido el acto cuya nulidad se declara, con costas del recurso.

Regístrese y devuélvase.

Redacción del Ministro Sr. Leopoldo Llanos Sagristá.

Rol No 1254-2004.

\section{Comentario}

La sentencia que se comenta fue dictada recientemente por la Corte de Apelaciones de Temuco, a propósito -como se desprende de la lectura del fallo- de la apelación de un fallo de primera instancia que rechazaba una demanda de rescisión de una partición por lesión enorme (amén de otros capítulos invalidatorios).

El fallo es relevante porque aborda dos cuestiones diversas de marcada de importancia doctrinal. La cuestión central sometida a consideración judicial se refiere a la posibilidad de impetrar, sobre la base del artículo 1348 del Código Civil (cuyo primer inciso sirve de epígrafe a este comentario), la nulidad o rescisión de una partición no efectuada por los interesados (a cuyo respecto la afirmativa no presenta duda alguna) sino por un juez partidor. Además, resuelve (rechazándola) una acción reconvencional de daños y perjuicios mediante la que los demandados de nulidad de la partición pretendían la reparación de los daños materiales y morales causados por la propia demanda. A esas dos cuestiones me referiré en los párrafos que siguen, en el mismo orden en que se han expuesto.

La primera pregunta relevante que contesta el fallo es si las particiones judiciales son también anulables en virtud del artículo 1348. La respuesta es significativa, porque pese a que la mayor parte de la doctrina sostiene la afirmativa, Pablo Rodríguez (Instituciones de Derecho Sucesorio) ha sostenido reiteradamente la posición contraria. Ese autor argumenta sosteniendo la indivisibilidad civil procesal del acto particional, y haciendo primar la fuerza de la cosa juzgada del fallo arbitral, por sobre la naturaleza civil del acto de partición.

En contrario, la sentencia de la Corte de Temuco vuelve a sentar la correcta doctrina de que la acción del artículo 1348, "como apunta el profesor Somarriva, se aplica a toda clase de partición, tanto a la hecha por el causante, por los comuneros de común acuerdo o por el partidor, y en este caso, 'no es óbice para demandar la nulidad de la partición fundada en el artículo 1348 el hecho que el laudo se encuentre ejecutoriado y aun aprobado judicialmente', agregando que 'la solución contraria equivaldría a transformar la nulidad civil en procesal, ya que se sanearía con la ejecutoria del laudo"” (Considerando Quinto). Este es un caso paradigmático, además, porque demuestra muy a las claras cómo es perfectamente posible que un laudo arbitral, respecto del que incluso 
se ha interpuesto apelación (declarada inadmisible), puede sin embargo no ajustarse a derecho, y resultar completamente razonable la posibilidad de impetrar respecto de la partición en él contenida una declaración de invalidez.

Al resolver esta cuestión, adicionalmente, la sentencia vuelve correctamente sobre la distinción -largamente asentada en nuestra doctrina y jurisprudencia, pero que la doctrina de Rodríguez Grez rechaza, y el fallo de la instancia había olvidado- entre las nulidades procesales y la nulidad civil, que es capital para la adecuada inteligencia del artículo 1348. Como apuntaba Somarriva, "el carácter híbrido de la partición hecha ante un partidor, donde se mezclan el contrato y el juicio, hace posible que puedan presentarse en ella vicios que ocasionen la nulidad civil, y otros que traigan consigo nulidades procesales. El artículo 1348, disposición de carácter sustantivo, no se aplica a los vicios de procedimiento. Sobre este punto, nuestros autores están totalmente de acuerdo”. Diferenciar es esencial, porque los vicios procesales se sanean automáticamente con la terminación definitiva del juicio, y su ulterior discusión queda vedada por la fuerza de la excepción de cosa juzgada. En cambio, los vicios sustantivos son susceptibles de reclamarse en juicio de nulidad o rescisión una vez ejecutoriada la sentencia, y mientras no opere la prescripción. En resumen, la nulidad sustantiva permite impugnar la partición como resultado, pero es inviable para impugnar el proceso por el que se llegó a ese resultado, para lo cual estuvieron abiertas las vías procesales franqueadas por la ley adjetiva.

La segunda cuestión relevante sobre la que se pronuncia la sentencia en comento, como se avanzó, es la relativa a la procedencia de una indemnización por daños materiales y morales, causados por la propia demanda, en sede reconvencional. La respuesta doctrinal y jurisprudencial tradicional a la pregunta por las condiciones en que el ejercicio de una acción judicial puede dar lugar a una indemnización civil por daños y perjuicios ha sido imputar responsabilidad cuando pueda considerarse que el ejercicio del derecho es abusivo, aunque resulta bastante oscura la respuesta acerca de cuándo pueda positivamente estimarse abusivo el ejercicio del derecho de acción. Por lo mismo, el problema del derecho subjetivo que al ejercerse causa un daño a terceros tiende en doctrina y en la jurisprudencia a resolverse utilizando múltiples parámetros de valor, como el de la utilidad (cuyo objetivo es imputar abuso cuando el ejercicio del derecho genera un daño a terceros, pero sin que exista utilidad para el titular), el de la buena fe (con el objetivo de postular que aún habiendo utilidad para el titular, si el ejercicio del derecho es malicioso, pueda generarse responsabilidad), el de la contravención del legítimo espíritu y ejercicio del derecho, el de la trasgresión de la finalidad social del derecho, y el más extendido, el de la culpa o dolo, o del delito o cuasidelito civil (que postula que sólo puede generar responsabilidad el acto del cual pueda predicarse que es constitutivo de delito o cuasidelito civil). La sentencia de primera instancia adhería a esta última posición: “(...) es posible concluir que el actuar del demandado reconvencional, al iniciar una acción peregrina y sin fundamento serio y demostrable en estrados judiciales, fue dolosa o a lo menos culposa, pues respetando el deber de cuidado y diligencia mínima, pudo haber advertido que dicha empresa generaría perjuicios en los destinatarios de las acciones judiciales emprendidas" (fs. 221).

Como se comprende, resulta de un automatismo palmario que al aceptarse la demanda de rescisión por lesión, debe rechazarse -como hizo bien la Corte- la demanda 
reconvencional de daños y perjuicios derivados del ejercicio de esa misma acción. Con todo, dada la naturaleza del derecho de acción, puede sostenerse la necesidad de que ese rechazo sea generalizable. En efecto, la acción se concibe ahora como el derecho a la actividad jurisdiccional, a que en el proceso llegue a dictarse una sentencia sobre el fondo del asunto, sea cual fuere el contenido de ésta. El único elemento indefectible en toda acción es el derecho a sujetar al demandado al proceso, y este derecho no se funda en el derecho material hecho valer mediante la acción, sino en la necesidad de subsistencia del orden jurídico, la interdicción de la autotutela, y en el derecho al mantenimiento de la paz social. Como este derecho mira preferentemente el interés de los débiles, es decir, de los necesitados de protección, y es un instrumento social cuya eficacia plena es consustancial al funcionamiento razonable de sociedades respetuosas de los derechos, ordenadas y estables, sólo debiera entenderse abusivo el ejercicio del derecho de acción cuando es el fuerte quien acciona contra el débil. Evidentemente que esa calificación no es posible de realizar, ni siquiera prima facie, en todos los casos. Estoy simplemente postulando que la circunstancia objetiva de tratarse de la acción del poderoso contra el débil se constituya como condición previa sine qua non para la referida calificación. Es evidente que se requiere algo más (de lo contrario ninguna parte fuerte de una relación jurídica podría compeler a la otra al cumplimiento forzado, por ejemplo), y me parece que aquí resulta imprescindible el recurso a criterios subjetivos como la mala fe (en la lectura subjetiva del artículo 706 del Código Civil) y el dolo. Es decir, puede postularse que un ejercicio abusivo del derecho de acción es aquel que realiza el poderoso contra el débil, con conciencia de estar obrando de modo ilegítimo, esto es, con ánimo positivo de perjudicar al otro de un modo que va más allá de lo tolerado por el ordenamiento jurídico. Asimismo, y considerando que los daños morales causados por la interposición de acciones judiciales son "perjuicios" de tolerancia necesaria (por la misma razón antes enunciada), no resultan compensables en sede aquiliana, porque no constituyen jurídicamente un daño a estos efectos, salvo que resulte acreditado que la víctima nunca fue un legítimo contradictor del actor en el proceso que causó los daños.

Finalmente, y aunque la sentencia en comento no se pronuncia expresamente sobre el punto, me parece necesario sostener que no resulta plausible que los daños morales y patrimoniales generados por una acción judicial sean reclamados en sede reconvencional. La interpretación contraria resulta inadmisible, en primer término, por una simple cuestión de lógica formal. Antes de la sentencia definitiva, firme y ejecutoriada, que resuelva con autoridad de cosa juzgada el conflicto, no es posible afirmar que una acción es infundada o imprudente. Por lo tanto, como es perfectamente posible que el demandante tenga después la razón (en la sentencia definitiva) no resulta tolerable que se le condene antes por no tenerla. O sea, puede concebirse una acción por daños extracontractuales derivados del ejercicio de acciones judiciales, pero jamás antes de que la acción en cuestión haya sido desechada por sentencia firme. Frente a una posible objeción de economía procesal se yerguen las consideraciones de política jurídica expresadas previamente, y otra de orden práctico: si se abre esa puerta, muy pocas contestaciones de demanda dejarían de incluir una demanda reconvencional indemnizatoria, con lo que el esfuerzo judicial global casi se vería duplicado, y la supuesta economía procesal, traicionada. 